\title{
A INSPETORIA DE EDUCAÇÃO FÍSICA DE MINAS GERAIS: ELEMENTOS DE COMPLEXIFICAÇÃO DA FORMAÇÃO DE PROFESSORAS PARA O ENSINO DA DISCIPLINA (1927-1937)
}

Giovanna Camila da Silva ${ }^{1}$

\begin{abstract}
Resumo
Este estudo investigou as ações de qualificação do professorado realizadas pela Inspetoria de Educação Física de Minas Gerais, no período de 1927 a 1937. As fontes foram constituídas pela legislação estadual, por periódicos de ação governamental e impressos sobre Educação Física. O texto apresenta as motivações para a criação de um órgão específico para organizar ações relativas à presença da Educação Física nas escolas, analisa o projeto empreendido pelos sujeitos que compuseram a Inspetoria, com destaque para o investimento central no aperfeiçoamento docente por meio de cursos intensivos e de circulação de impressos, e ainda discorre sobre o declínio de tal órgão. Nas ações de formação de professoras é possível afirmar que a Inspetoria ultrapassou os limites de subsídios eminentemente práticos e alargou os conhecimentos das professoras responsáveis por ministrar Educação Física nas escolas.
\end{abstract}

Palavras-chave: Educação Física. Formação Docente. História da Educação.

\footnotetext{
${ }^{1}$ Doutora em Educação. Universidade Federal de Minas Gerais. OECID: https://orcid.org/0000-0002-5705-0573.

E-mail: giovannaufmg@yahoo.com.br
} 


\title{
INSPETORIA DE EDUCAÇÃO FÍSICA DE MINAS GERAIS: ELEMENTS OF COMPLEXIFICATION OF FEMALE TEACHER TRAINING FOR THE TEACHING OF PHYSICAL EDUCATION (1927-1937)
}

Giovanna Camila da Silva

\begin{abstract}
This study investigated the actions made by the Inspetoria de Educação Física de Minas Gerais in teacher training between 1927 and 1937. The sources mobilized for this project were: official documents, journals of governmental action and printouts about Physical Education. The text presents the motivations behind the creation of a specific institution to organize actions related to Physical Education in schools, analyzes Inspetoria's central investment in teacher training through courses and printouts, and discusses the decline of the institution. In female teacher training actions, the Inspetoria has exceeded the limits of eminently practical subsidies and has expanded the knowledge of female teachers responsible for teaching Physical Education in schools.
\end{abstract}

Keywords: Physical Education. Teacher Training. History of Education. 


\title{
LA INSPETORIA DE EDUCAÇÃO FÍSICA DE MINAS GERAIS: ASPECTOS MÁS COMPLEJOS EN LA CAPACITACIÓN DE MAESTROS PARA ENSEÑANZA DE LA MATERIA (1927-1937)
}

Giovanna Camila da Silva

\begin{abstract}
Resumen
Este estudio investigó las acciones de capacitación de maestros realizadas por la Inspetoria de Educação Física de Minas Gerais, desde 1927 hasta 1937. Las fuentes fueron formadas por leyes del Estado, por publicaciones periódicas de acción gubernamental e impresos sobre Educación Física. El texto presenta las motivaciones para la creación de un organismo institucional específico para organizar acciones relacionadas con la presencia de la Educación Física en las escuelas, analiza el proyecto desarrollado por la Inspetoria, con énfasis en inversión central en la capacitación de maestros a través de cursos intensivos y circulación de material impreso, y analiza además el declive de tal organismo institucional. Es posible afirmar que la formación del profesorado fue más allá de los límites de las contribuciones eminentemente prácticas y amplió los conocimientos de los maestros encargados de la Educación Física en las escuelas.
\end{abstract}

Palabras clave: Educación Física. Capacitación de maestros. Historia de la Educación. 


\section{Introdução}

A Inspetoria de Educação Física de Minas Gerais pode ser considerada o primeiro órgão no Estado dedicado especialmente às iniciativas de escolarização da disciplina. Sua criação e o desenvolvimento de suas ações deram-se em um momento de renovação pedagógica ancorada no ideário de uma escola mais ativa e sedutora para os alunos. A intervenção nos sistemas públicos de ensino processou-se no decorrer dos anos de 1920, em diferentes centros urbanos. Operando uma mudança na função social da escola, a qual já não bastava ensinar a ler, escrever e contar, as representações produzidas pelos educadores e reformadores brasileiros organizavam a escola como lugar de permanente diálogo com o meio social. Nesse contexto, a Inspetoria de Educação Física foi instituída pelo Decreto $\mathrm{n}^{\circ}$ 7.970-A, de 15 de outubro de 1927. Tratava-se do aparato legal que aprovava o Regulamento do Ensino Primário, um dos documentos que consubstanciou a Reforma do Ensino Primário em Minas Gerais naquele ano. Marta Maria Chagas de Carvalho (2007), ao comentar algumas reformas da instrução pública implementadas no país naquele período, assevera que a Reforma Mineira incorporou “uma 'revisão dos fins sociais’ da escola, calcada (...) em uma ‘nova compreensão da vida’ e da ‘transformação social’ que se processava naqueles anos” (p. 247). Tomando-se o caso de Minas, a remodelação da escola enfatizou a centralidade da infância nas práticas educativas e um conjunto de medidas voltado para a qualificação de docentes, pautada nos novos métodos pedagógicos².

Esta investigação analisou como a Inspetoria no período de sua existência, de 1927 a 1937, investiu no processo de escolarização da Educação Física, especialmente pelas iniciativas de qualificação do professorado que se ocupava do ensino da disciplina. Busco a contribuição de Faria Filho $(2003,2007)$ para explicitar o uso da expressão “escolarização da Educação Física”. Segundo o autor o termo escolarização pode ser entendido em três acepções, que, mesmo interrelacionadas, guardam alguma particularidade. Destaco para este estudo dois sentidos, por ligarem-se estreitamente à ação fundamental que a Inspetoria desenvolveu para seu projeto de Educação Física: a necessidade de especialização das professoras.

Conforme Faria Filho (2003, 2007), um primeiro sentido para escolarização refere-se aos processos que estabeleceram instituições responsáveis pelo ensino formal de diferentes saberes. Tal acepção fomenta este estudo a partir da constatação de que a Inspetoria de Educação Física se configurou, em Minas Gerais, como a primeira instituição responsável pela formação

\footnotetext{
${ }^{2}$ Carvalho (2007) cita algumas iniciativas do governo mineiro a fim de melhor formar o professorado: a remodelação da Escola Normal, a criação da Escola de Aperfeiçoamento que se dedicava ao ensino de normalistas já formadas, a reformulação da Revista do Ensino e a organização de bibliotecas.
} 
específica das professoras que ministrariam a disciplina nas escolas. Em um segundo sentido, o termo escolarização é entendido como “o processo e a paulatina produção de referências sociais, tendo a escola, ou a forma escolar de socialização e transmissão de conhecimentos, como eixo articulador de seus sentidos e significados” (FARIA FILHO, 2003, p. 78). Aqui, conforme destaca o autor, ganham relevo as questões relacionadas à emergência da profissão docente no Brasil. Essa foi uma noção importante para interpretar as fontes, que, por vezes, referem-se a um “aparecimento” da professora de Educação Física, reportando-se a essa especificidade, constantemente defendida pela Inspetoria, como algo relativamente novo. Alguns antecedentes mostram-se necessários para esse entendimento.

Em dezembro de 1906 foi criada a Escola Normal Modelo da Capital, frequentada apenas por mulheres. Todavia, no seu programa, não estava prescrito o ensino de ginástica ${ }^{3}$. Essa suspensão estava presente desde dezembro de 1898, quando o Estado dispensou os professores que ministravam ginástica nas Escolas Normais, com o propósito de reduzir despesas públicas (VAGO, 1997). Em um primeiro momento, é possível interpretar a iniciativa do Estado como ambígua, uma vez que os Exercícios Físicos estavam presentes no programa de ensino primário, mas ausentes da formação de professoras. Ao buscar alternativas para compensar o suposto contrassenso, fez circular algumas obras sobre ginástica nas escolas isoladas e nos grupos escolares de Minas Gerais. Mas, analisando essa ação do Governo Mineiro por outro prisma, é preciso considerar a compreensão que orientava o ensino de tal prática nas escolas e quais as competências requeridas às professoras para ministrar a matéria. É possível pensar que, nesse momento, os Exercícios Físicos nos grupos escolares não reclamavam formação particularizada para proceder ao seu ensino. Não havia uma demarcação do que seria formar o professorado para atuar com a disciplina, e, talvez, seu caráter fosse tão eminentemente prático que a distribuição de manuais de ginástica cumprisse a função de qualificar o corpo docente para ministrar a matéria nas escolas. Nesse momento, os Exercícios Físicos apresentam pequeno grau de formalização no ensino. É com o decorrer dos anos que essa prática vai ganhando complexidade e especializando-se, o que acarretou um clamor pelo aperfeiçoamento cada vez maior do corpo docente.

Tarcísio Mauro Vago (1997) indica que o retorno da ginástica aos programas de ensino das escolas normais acontece em 1910, quando incluída nos programas da Escola Normal da Capital e nas demais escolas normais do Estado, que também se mantinham exclusivas para mulheres. Em 1916, o

\footnotetext{
3 A partir de meados da década de 1920, "Educação Física” era a expressão cada vez mais comum para nomear as práticas corporais sistematizadas nas escolas. Antes disso, o termo "Exercícios Físicos" era usual para designar a matéria na qual a "ginástica" era uma prática privilegiada.
} 
Decreto $\mathrm{n}^{\circ}$ 4.524, de 21 de fevereiro, regulamentou o ensino normal em Minas Gerais. Nele, a ginástica permanecia inserida entre as cadeiras de ensino. Seu programa propunha como conteúdos a ginástica sueca, os jogos, as danças e os brinquedos infantis. O Decreto n. 4.955, de 03 de abril de 1918, manteve a ginástica como componente do programa do ensino normal no Estado de Minas Gerais. A inserção da ginástica na formação de professoras tinha uma dupla tarefa: “aperfeiçoar (conformar) o físico das alunas e prepará-las para o magistério nas escolas primárias” (VAGO, 1997, p. 53).

No ano de 1916 o diretor da Escola Normal Modelo, Arthur Joviano, apontou em relatório do Secretário do Interior enviado ao Presidente do Estado, uma constatação preocupante em relação à execução do programa de ensino primário. O diretor indicava que a ginástica estava condicionada a figurar como "lettra morta” nas escolas. "Lettra” porque, na então recente reforma do ensino primário promovida em 1912, a ginástica permanecia inserida nos programas. "Morta” porque a prescrição legal, muitas vezes, não estava presente nas práticas escolares (VAGO, 1997). Aqui, Arthur Joviano coloca em evidência o trabalho das professoras que relegavam a ginástica para um plano secundário, por não se sentirem com a mesma responsabilidade para com a matéria. Pode-se supor que a ausência de formação específica para ministrar aulas de ginástica teria contribuído para o descaso com sua prática nas escolas, e, nesse sentido, Arthur Joviano defendia, naquele mesmo documento, a especialização docente para as diferentes disciplinas do programa.

Foi a partir desse cenário de precariedades que cada vez mais foi-se produzindo a necessidade de uma professora qualificada, bem informada e especializada em Educação Física. Logo, a Inspetoria ao propor insistentemente ações para qualificar o professorado, produziu novas referências para o ensino da disciplina.

A pesquisa mobilizou um conjunto documental constituído por diferentes fontes, destaquem-se: aparatos legislativos do governo mineiro; o Jornal Minas Gerais, órgão oficial do Estado, que publicava diferentes iniciativas da Inspetoria; a Revista do Ensino de Minas Gerais, uma das estratégias do Governo Mineiro para a divulgação da sua política educacional; o Boletim Pedagógico n. 18, publicado pela Secretaria da Educação e Saúde Pública, intitulado Educação Física - Jogos e Calistenia, que contou com a contribuição da Inspetoria.

\section{Por que uma Inspetoria de Educação Física?}

Elementos de fragilidade marcaram os momentos iniciais da constituição da ginástica como campo disciplinar em Belo Horizonte e diferentes entraves foram encontrados para sua real concretização nas escolas, nas décadas iniciais do século XX: 
Inexistência de espaços físicos, conforme previsto na legislação, participação na distribuição dos tempos escolares reduzida ou desconsiderada, secundarização de seu ensino em relação a outras cadeiras do programa, dúvidas entre sua obrigatoriedade ou facultatividade, professoras sentindo-se despreparadas e sem condições de ensiná-la; esses são exemplos das circunstâncias, relatadas por diretoras e inspetores, em que seu ensino esteve envolvido nos primeiros momentos de sua inserção escolar em Belo Horizonte (VAGO, 2002, p. 348).

Pensada a partir da expectativa de reorganização da instrução em Minas Gerais e instaurada pela Reforma do Ensino Primário de 1927, a Inspetoria de Educação Física integrava um projeto que reconfigurava o processo educativo no Estado. Diante da incumbência de organizar a instrução primária, Francisco Campos, Secretário do Interior à época, constituiu o primeiro Congresso de Instrução Primária de Minas Gerais, considerado um trabalho preparatório para a Reforma de 1927, na medida em que suas inspirações, sugestões e conclusões foram ponto de partida para a remodelação do ensino em Minas. O Congresso foi realizado entre os dias 9 e 18 de maio de 1927 e doze comissões foram formadas para discutir matérias específicas e apresentar conclusões sobre as teses que estariam em questão: Organização Geral do Ensino; Questões de Pedagogia; Instituições Auxiliares de Escola; Aparelhamento Escolar, livros didáticos e livros para professores; Desenho e Trabalhos Manuais; Educação Moral e Cívica; Canto; Inspeção Técnica; Programas e Horários; Higiene Escolar e Educação Física, Exames e Testes; Escolas Infantis.

As comissões tinham o intuito de estudar e discutir assuntos específicos relativos ao ensino primário. A análise de sua composição e do debate por elas promovido permite evidenciar deliberações por saberes em que a dimensão educativa passava pelo corpo: Trabalhos Manuais, Desenho, Canto, Higiene, Educação Física (SILVA, 2009). Essa é uma importante consideração para compreender a criação da Inspetoria de Educação Física. Sua existência guarda estreita relação com uma ambiência de renovação pedagógica, na qual prescrições de práticas de educação do corpo compuseram as dinâmicas de reorganização do ensino em Minas Gerais.

Do processo de organização e realização do Congresso de Instrução Primária, interessou analisar a discussão da comissão que tratou dos assuntos particulares da Educação Física. As teses organizadas pela comissão de Higiene e Educação Física foram as seguintes:

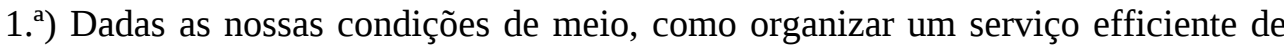
inspecção medica escolar?

2. a) Deverá a inspecção medica extender-se ao corpo docente e ao pessoal administrativo das escolas?

3. ${ }^{\text {a) }}$ Como formar um corpo de enfermeiras escolares efficientes?

$\left.4 .^{a}\right)$ Quaes os meios mais convinhaveis para que se inculquem nos escolares os hábitos sadios de hygiene individual e para que se forme nelles a "consciencia sanitaria”?

5. $\left.{ }^{a}\right)$ Como introduzir na escola primaria a cultura physica necessária á nossa gente? 
6. ${ }^{\text {a) }}$ Qual o tempo a ser destinado, no horario, á educação physica?

7.") O “escoteirismo” poderá dar entrada na escola primaria, como meio de educação moral e physica?

8. $\left.{ }^{a}\right)$ Os methodos de educação physica deverão ser os mesmos para todos os annos do curso primário? (Jornal Minas Geraes, 1926b, p. 6).

As fontes permitem ver uma tensão entre as experiências dos sujeitos que compunham a comissão e que estavam ali construindo os rumos da escolarização da Educação Física no Estado. Pertencentes a diferentes lugares sociais, eles compartilharam e disputaram sentidos para o ensino da matéria ${ }^{4}$. Passados os dias de debate, as conclusões convencionadas no evento foram:

a) a educação physica deve ser parte integrante e não complementar do programma das escolas publicas primarias;

b) deve ser disciplina obrigatoria e ministrada diariamente, por professores competentes, conhecedores do exercicio e seu mechanismo, capazes de realizal-os bem, enthusiastas do ensino;

c) incluir nos programmas escolares uma hora especial para a educação physica;

d) organizar em cada escola um campo especial para a pratica da cultura physica;

e) instituir a inspecção medica;

f) organizar fichas anthropometricas, annualmente;

g) nomear professores especializados para a educação physica;

h) fornecimento de material necessario, de modo que todos os alumnos façam exercicios com objectos de um mesmo typo;

i) constituir uma commissão que, sujeita a um criterio unico, ministre a educação physica em aulas, que serão, depois, repetidas pelos professores que se encarregarem dessa disciplina;

j) a gymnastica rythmica poderá ser introduzida nas escolas primarias (Revista do Ensino, 1927, p. 502).

A ideia de “constituir uma commissão” para tratar detidamente a Educação Física indicia sobre uma tentativa de autorização e legitimação de um saber que reclamava especificidades. As conclusões acordadas no Congresso de Instrução Primária se traduziram no texto da Reforma do Ensino na criação da Inspetoria de Educação Física de Minas Gerais. Suas finalidades estavam intimamente relacionadas à instituição escolar, aos processos educativos, às dinâmicas de escolarização. A ela competia:

a) organizar programmas e horarios de exercicios, jogos, gymnastica, etc., de accordo com as estações e circumstancias locaes, edade e desenvolvimento physico das creanças;

b) organizar instrucções para a orientação dos professores de educação physica e inspeccionar as respectivas aulas;

c) ministrar na Capital um curso especial para formação e aperfeiçoamento do pessoal docente destinado ao ensino da educação physica;

d) organizar, de accordo com a Inspectoria Medica, classes especiaes de educação physica para creanças mal constituidas, debeis organicos, defectivos mentaes e portadores de defeitos orthopedicos;

\footnotetext{
${ }^{4}$ Para conhecer os sujeitos que se envolveram com a comissão de Higiene e Educação Física e maiores detalhes da discussão, cf. Silva (2009).
} 
e) collaborar nos programmas e na organização das excursões escolares, prescrevendo e recommendando os jogos e exercicios physicos adequados;

f) propôr a acquisição dos apparelhos e materiaes apropriados ás diversas classes de educação physica;

g) estabelecer na Capital e nas outras cidades praças de exercicios physicos convenientemente localizadas para que possam concorrer a ellas todos os alunos das escolas publicas, devendo cada praça ser dirigida por um dos auxiliares, designados pelo inspector;

h) incentivar e orientar a organização do escoteirismo nas escolas publicas, formando e preparando o necessario corpo de instructores” (Minas Gerais, 1928, p. 1170-1171).

Diferentes foram os sujeitos que colocaram em funcionamento tal órgão. Entre os que podem ser chamados de protagonistas estão o Inspetor de Educação Física, Renato Eloy de Andrade, e suas auxiliares: Guiomar Meirelles, Diumira Campos de Paiva, Zembla Soares de Sá. A quase totalidade das pessoas envolvidas com o projeto de intervenção da Inspetoria passou por uma formação na qual a sintonia com as teorias pedagógicas estava presente. As mulheres chamadas a ali colaborar atuaram com o ensino primário. Já em 1914 a professora Guiomar foi designada para ministrar aulas de ginástica em um grupo escolar da capital. Em 1929, Zembla Sá assumiu o cargo de assistente técnica de ensino e tinha como dever propagar e executar os princípios da Reforma. Diumira Paiva foi aluna da Escola Normal Sagrado Coração de Jesus e recebeu seu diploma de normalista em dezembro de 1927. Em seguida, estudou na Escola de Aperfeiçoamento, onde diplomou-se em dezembro de 1931. Já o Inspetor, Renato Andrade, manteve relação com a Associação Cristã de Moços e ali estudou em cursos para formação de diretores físicos nas escolas da instituição em Chicago e em Montevidéu (SILVA, 2009).

Esse grupo de trabalho produziu novas balizas pedagógicas para a Educação Física e demarcou posições no processo de formação do professorado que ministraria a matéria. No período de existência da Inspetoria, ocorreu um conjunto de novos sentidos para a escolarização da Educação Física em Minas.

\section{A formação de professoras para o ensino de Educação Física}

As iniciativas com a Educação Física produzidas pela Inspetoria não aconteceram simultaneamente e não ganharam a mesma visibilidade no órgão oficial do Estado. Os cursos intensivos e a publicação de impressos para qualificar as professoras responsáveis pelo ensino da matéria foram os empreendimentos de maior fôlego promovidos pelo órgão ${ }^{5}$. Dois momentos podem ser destacados para a iniciativa dos cursos intensivos de Educação Física. O primeiro,

\footnotetext{
${ }^{5}$ Para conhecer o arranjo de ações articulado pela Inspetoria de Educação Física, cf. Silva (2009).
} 
compreende aqueles realizados entre 1928 e 1932, no qual tal ação parece assemelhar-se mais a uma tentativa de perceber se a iniciativa lograria êxito e a uma espécie de possibilidade de despertar no professorado o interesse pelo seu aperfeiçoamento. Já as iniciativas realizadas em 1933 e em 1934 podem configurar-se como um segundo momento de organização dos cursos, uma vez que tais acontecimentos abrangeram maior número de docentes e tiveram sua estrutura de organização bastante similar. Esse é o período de maior sistematização e normatização na realização dos cursos. Para estes, uma série de instruções foram publicadas pelo jornal Minas Gerais, na seção da Secretaria da Educação e Saúde Pública, destinadas ao professorado do Estado que vislumbrasse fazer parte da formação especializada. Poderiam efetuar a matrícula, as professoras responsáveis pelo ensino de Educação Física. Além de cumprir esse quesito, outras condições deveriam ser atendidas:

a) ser normalista diplomada por escola oficial ou reconhecida pelo Estado;

b) ter mais de 16 anos de idade e menos de 30;

c) ter demonstrado capacidade especial para ministrar o ensino de Educação Fisica, com atestados firmados pelos diretores dos estabelecimentos onde haja trabalhado ou por assistentes técnicos;

d) ter robustez fisica compativel com a natureza do trabalho que terá de executar, atestada por medico escolar (Jornal Minas-Gerais, 1933, p. 4).

Nos itens para matrícula no curso, a evidência da produção de contornos específicos para o aperfeiçoamento docente. Para serem qualificadas pela Inspetoria, era necessário que as professoras tivessem já de antemão certo domínio de conhecimentos e habilidades adquiridas quando de sua formação como normalistas. O diploma do curso normal, além de instrumento de ingresso à carreira do magistério, configurava-se nessa iniciativa como condição para a continuidade dos estudos. Outro aspecto a ser ressaltado são as características desejáveis ao professorado da matéria. Possivelmente, a “capacidade especial para ministrar o ensino de Educação Fisica” refere-se a alguns atributos que seriam “perfeitamente dispensaveis áquelles que se dedicam a outras disciplinas” (Revista do Ensino, 1925, p. 186). Além desses predicados, como habilidade, destreza e bom humor, a constituição corporal era requisito imprescindível, visto que avaliada e comprovada por um médico.

De um modo geral, às professoras eram ensinados conteúdos para serem trabalhados nas aulas de Educação Física: a calistenia que tinha uma tríplice função - preventiva, corretiva e disciplinadora -, e os jogos porque, além de interessar aos instintos infantis, por meio deles “se ensinam praticamente as leis cujos principios basicos se encontram nos códigos sociaes” (Jornal Minas Geraes, 1928, p. 9). Além disso, o desenvolvimento dos cursos acarretou mudanças nas competências necessárias ao trabalho de ensinar Educação Física nas escolas. O conhecimento 
eminentemente prático que marcava a ação docente nos momentos iniciais de escolarização da Educação Física, passava a dividir espaço com os processos e métodos de ensino, com os conhecimentos biológicos e da psicologia. Reiterando essa perspectiva, a Revista de Educação Física, publicada pela Escola de Educação Física do Exército, em 1934, anunciava sobre o curso intensivo realizado no ano anterior: "Por deferência especial do Dr. Renato Elói de Andrade, Inspetor da Educação Física em Minas” foram remetidos à Revista documentos nos quais se identifica a "clara finalidade do curso, que é preparar intelectual e tècnicamente as professoras, capacitando-as a bem desempenharem as suas funções no magistério mineiro, sob uma orientação moderna e científica” (Revista de Educação Física, 1934, p. 25). Um fragmento do programa de ensino do curso apresenta a pretendida perspectiva de formação mais ampliada:

Didática e pedagogia da educação física, sob os títulos:

I - Nomenclatura dos movimentos;

II - Direção e planos para os movimentos;

III - Fisiologia e mecânica dos movimentos;

IV - Progressão dos movimentos, quanto às possibilidades anátomo-mecânicas e neuro-musculares;

$\mathrm{V}$ - Teoria e técnica da confecção das séries de exercícios.

VI - Valores psicológicos e fisiológicos das atividades usadas pela educação física, que sob o ponto de vista do educando, quer sob o ponto de vista de sua relação com a sociedade.

VII - Estudos dos valores sociais das diversas atividades físicas e suas aplicações específicas nos trabalhos de socialização escolar: - 1 - a marcha e a calistenia, como fatores da educação do sentido, da beleza e do ritmo coletivo; 2 - os jogos pequenos, como elemento de expansão e exteriorização da personalidade; 3 - os grandes jogos, como elemento fundamental na educação e adaptação das faculdades de assimilação e identificação do educando, com os sentimentos, ideais e comportamento sociais.

VIII - Estudos e aplicações das possibilidades da Educação Física, como fator auxiliar do desenvolvimento intelectual: - sua relação com todas as matérias do ensino e seus valores pedagógicos como auxiliares; - seu papel como elemento de emulação e fixação de hábitos de higiene individual e social.

IX - Estudos das regras dos jogos desportivos; organização e administração da educação física escolar (Revista Educação Física, 1934, p. 26).

Na história da escolarização da Educação Física em Minas Gerais, parece ser a primeira vez que se produziu um empreendimento que pretendeu alargar os conhecimentos das professoras encarregadas de ministrar Educação Física nas escolas e que ultrapassou os limites de subsídios eminentemente práticos.

A insistência em formar professoras especializadas em Educação Física, especialmente pela realização de cursos intensivos, pode ser considerada no Estado como momento inicial da preocupação com uma composição de saberes específicos, que aliava os conteúdos aos métodos e processos de ensino para ministrar tal disciplina nas escolas. Esse movimento pode ter 
configurando-se como terreno fértil para as proposições de ensino superior para tal profissão. Indício dessa fecundidade é um fragmento presente no documento "Necessidade da criação da Escola de Educação Física e Desportos de Minas Gerais”, de 1947, no qual a iniciativa de formar professoras promovida pela Inspetoria é destacada.

Merece ser recordado que no Estado de Minas, já foram realizados cinco cursos intensivos, destinados às professoras dos grupos escolares do Estado, cursos dirigidos e organizados pela Inspetoria de Educação Física da Secretaria da Educação, a cuja frente se achava Renato Eloy de Andrade. O 5. ${ }^{\circ}$ curso foi instalado a 11 de setembro de 1933 e encerrado a 30 de novembro do mesmo ano, funcionando com uma matrícula de 140 alunas. Até hoje sentimos os benefícios de tais cursos (Necessidade..., 1947, p. 11) ${ }^{6}$.

A ênfase dada ao trabalho da Inspetoria compunha um conjunto de argumentos reunidos para justificar uma instituição de formação em Educação Física. Os signatários do documento, professores diplomados pela Escola de Educação Física do Exército e pela Escola Nacional de Educação Física e Desportos, indagavam a não existência de uma Escola do gênero em Minas Gerais, quando o desenvolvimento esportivo no Estado reclamava técnicos para atuarem nas escolas, nas praças de esportes e em outros espaços da cidade. Vestígio do lastro que as proposições da Inspetoria parecem ter produzido para o ensino de Educação Física nos anos posteriores ao seu desaparecimento.

Dando continuidade à iniciativa de qualificar o professorado, a Inspetoria envidou esforços para a produção de textos formativos. Elegendo a Revista do Ensino de Minas Gerais e o Boletim Pedagógico n. 18 "Educação Physica (Jogos e Callisthenia)” como fontes centrais para esse momento da investigação, foi possível perceber como os impressos anunciavam um projeto para o ensino de Educação Física e o quanto constituíram-se como produções que foram, oficialmente, encaminhadas a seus leitores. A Revista atingia números extensos de professoras na capital e no interior de Minas e o Boletim contou com essa circulação para ser distribuído por todo o Estado. “A Inspectoria de Educação Physica fez remetter, por intermedio da 'Revista do Ensino', o boletim nº 18, da Secretaria da Educação - (Jogos e Calistenia) - ás seguintes professoras: (...)” (Jornal Minas Geraes, 1935, p. 4). Na relação de envio, a indicação de remessa a docentes de 77 cidades de Minas.

Considerando os treze textos publicados pelos agentes da Inspetoria na Revista do Ensino, é possível considerar que estes sujeitos colaboraram para a ilustração do professorado e para a direção do ensino no Estado, como determinavam as orientações reformistas.

\footnotetext{
${ }^{6}$ Documento presente no acervo do Centro de Memória da Educação Física, do Esporte e do Lazer (CEMEF/UFMG).
} 


\section{Quadro 1 - Artigos de autoria de integrantes da Inspetoria de Educação Física publicados na Revista do Ensino}

\begin{tabular}{|c|c|c|}
\hline Título do artigo & Autoria & $\begin{array}{c}\text { Ano de } \\
\text { publicação }\end{array}$ \\
\hline Educação Physica - Marchas & Renato Eloy de Andrade & 1928 \\
\hline $\begin{array}{l}\text { Educação Physica - Jogos } \\
\text { Gymnasticos }\end{array}$ & Guiomar Meirelles & 1929 \\
\hline Educação Physica & Renato Eloy de Andrade & 1929 \\
\hline Educação Physica - Jogos menores & Adaptação de Renato Eloy de Andrade & 1929 \\
\hline Educação Physica - Callisthenia & Renato Eloy de Andrade & 1929 \\
\hline $\begin{array}{l}\text { Educação Physica - Ginástica } \\
\text { historiada }\end{array}$ & Guiomar Meirelles & 1931 \\
\hline $\begin{array}{c}\text { Objetivos na organização e } \\
\text { administração da Educação Fisica } \\
\text { escolar }\end{array}$ & $\begin{array}{c}\text { Renato Eloy de Andrade, Guiomar Meirelles e Zembla } \\
\text { Soares de Sá }\end{array}$ & 1931 \\
\hline Corpo de leaders & $\begin{array}{l}\text { Renato Eloy de Andrade, Guiomar Meirelles e Zembla } \\
\text { Soares de Sá }\end{array}$ & 1931 \\
\hline $\begin{array}{l}\text { Excursão e sua relação com a } \\
\text { Educação Fisica }\end{array}$ & $\begin{array}{c}\text { Renato Eloy de Andrade, Zembla Soares de Sá e } \\
\text { Guiomar Meirelles }\end{array}$ & 1932 \\
\hline Para a gymnastica historiada & Contribuição da Inspectoria de Educação Physica & 1935 \\
\hline $\begin{array}{l}\text { A Educação Physica tratada em } \\
\text { Congresso }\end{array}$ & Renato Eloy de Andrade & 1935 \\
\hline Educação Physica na escola primaria & Diumira Campos de Paiva & 1935 \\
\hline $\begin{array}{l}\text { Inspetoria de Educação Fisica - } \\
\text { Portaria n. } 1\end{array}$ & Renato Eloy de Andrade & 1937 \\
\hline
\end{tabular}

Fonte: Silva (2009).

Tais textos contemplaram tanto a parte ‘doutrinária’ quanto a ‘noticiosa’ que compunha a Revista. Na primeira, os integrantes da Inspetoria publicaram artigos que apresentavam novas abordagens para a Educação Física, insistiram na necessidade de organização do ensino e ainda esboçaram maneiras de ministrar a disciplina. Trabalhos originais, como o apresentado no VII Congresso Nacional de Educação (CNE), promovido pela Associação Brasileira de Educação (ABE), também foram ali divulgados. Na segunda parte, além de divulgar instruções oficiais, a Inspetoria de Educação Física publicou informações acerca de eventos e ocorrências nacionais. A compreensão dessa produção como mais uma iniciativa para a qualificação docente encontra respaldo nos estudos de Miguel Fabiano de Faria (2009) que permitiram afirmar que a Revista do Ensino se constituiu como uma estratégia de formação de professores para o ensino de Educação Física. O autor argumenta que este periódico educacional produziu e fez circular prescrições de práticas, representações de Educação Física e dos sujeitos escolares - especialmente professores e alunos - envolvidos com a matéria. No projeto de escolarização da Educação Física constituído na Revista do Ensino, como pesquisou Faria (2009), a Inspetoria ocupou um lugar importante.

Uma produção que integrou um conjunto de publicações organizado pela Secretaria da Educação e Saúde Pública, foi o Boletim n. 18: "Educação Physica (Jogos e Callisthenia) - uma contribuição da Inspetoria de Educação Física”. Este documento foi encontrado na seção de obras 
raras da biblioteca da Faculdade de Educação da UFMG inserido em uma encadernação intitulada “Boletins Pedagógicos”. A listagem dos títulos, que vai do primeiro número até o 20, evidencia a presença central da pedagogia e da psicologia orientando tais publicações. Significativo é compreender por que motivos, nesse contexto, tornou-se interessante publicar um Boletim Pedagógico que tivesse por temática a Educação Física. Uma hipótese a ser considerada é a insistente preocupação da Inspetoria em afirmar que a psicologia se configurava como uma ciência basilar para a orientação do ensino. Fosse para agrupar os alunos em classes homogêneas, fosse para conhecer o desenvolvimento e os interesses das crianças, e ainda, a fina sintonia entre os jogos e os instintos infantis.

Quadro 2: Artigos publicados no Boletim n. 18 “Educação Physica (Jogos e Callisthenia)”

\begin{tabular}{|c|c|}
\hline Título do artigo & Autoria \\
\hline O espirito e o systema neuro muscular & Renato Eloy de Andrade \\
\hline Educação physica e a futura raça brasileira & José Lourenço de Oliveira \\
\hline A educação physica applicada ao sexo feminino & Zembla Soares de Sá e Guiomar Meirelles \\
\hline Valor dos jogos & \begin{tabular}{c} 
Diumira Campos de Paiva \\
\hline O uso dos jogos
\end{tabular} \\
\hline Calistenia & $\begin{array}{c}\text { Renato Eloy de Andrade, Guiomar Meirelles, Zembla Soares de Sá } \\
\text { e Diumira Campos de Paiva }\end{array}$ \\
\hline Andrade
\end{tabular}

Fonte: Silva (2009, p. 167).

Dos seis textos publicados no Boletim, é possível enfatizar a recorrência na produção de elementos para a constituição da Educação Física nas escolas. A Inspetoria dava continuidade em suas ações para proporcionar ao professorado instruções, diretivas e recomendações para o efetivo ensino de Educação Física: prescrição de conteúdos, orientações científicas e possibilidades de aplicação. Renato Eloy de Andrade explicitava no Boletim n. 18 que “comprehende-se, pois, a importancia que se deve attribuir á Educação Physica e o esforço que o nosso Estado está empregando para a rodear das condições necessarias a uma elevada efficiencia em nosso meio educacional” (Boletim..., 1935, p. 7). O Boletim “Educação Physica (Jogos e Callisthenia)” e os artigos publicados na Revista do Ensino podem ser considerados parte desse empenho.

Para a análise dos impressos destinados às professoras de Educação Física, o argumento de Isabel Cristina Frade e Ceris Ribas da Silva (1998) mostra-se orientador para compreender a dinâmica dos artigos que circularam na Revista do Ensino e no Boletim n. 18 “Educação Physica (Jogos e Callisthenia)”7. As autoras, ao tratarem da leitura de textos oficiais, apontam que no caso

${ }^{7}$ Para uma análise mais detalhada dos textos da Inspetoria de Educação Física publicados na Revista do Ensino e no Boletim, ver Silva, 2009. 
de tais produções "não é o leitor quem busca espontaneamente o texto, mas é o texto que vai oficialmente ‘em busca’ de seus leitores” (FRADE; SILVA, 1998, p. 97). A Revista e o Boletim n. 18 eram publicações de órgãos subordinados à Secretaria da Educação e Saúde Pública. A primeira, a partir de 1927, ficou a cargo do Inspetor Geral da Instrução Pública e o segundo contou com a colaboração da Inspetoria de Educação Física. A destinação ao professorado, a indicação de práticas pedagógicas decorrentes da política educacional e a finalidade de orientar o trabalho docente marcaram a produção desses impressos.

\section{O declínio da Inspetoria}

Aos poucos, os empreendimentos da Inspetoria foram perdendo vigor e ela parecia perecer. Em algum tempo, houve a necessidade de concentrar o trabalho em atividades menos custosas e mais de caráter de gabinete. Para o ano de 1935, existe no jornal Minas Gerais uma lacuna de informações que indiciassem sobre os cursos intensivos. Em 1936, tal iniciativa foi anunciada e algumas atividades iniciais para a concretização do curso foram elaboradas, contudo, não foi realizado. Para o ano de 1937, nenhuma pista de que tal atividade tenha sido efetivada. É também possível perceber uma remissão na publicação de textos na Revista do Ensino

O estudo do declínio da Inspetoria demandou um arranjo de indícios, uma vez que não foi localizada documentação que explicitamente apontasse sua supressão. Uma indicação importante do distanciamento entre o Inspetor de Educação Física e o Governo de Minas é o decrescente número de encontros de Renato Andrade com os ocupantes de diferentes cargos de secretariado do Estado. Desde que assumiu como Inspetor, ele regularmente conferenciava com algum ocupante de cargo oficial, especialmente, o Inspetor Geral da Instrução e o Secretário da Educação e Saúde Pública. Por vezes, o encontro aconteceu no Palácio, com o próprio chefe do Estado ou com sua secretaria. No entanto, a partir de 1934, é contundente a menor incidência dessas reuniões (SILVA, 2009).

Em 1935, Renato Andrade explicitava seu descontentamento com o governo em função da (não) participação do Estado no VII Congresso Nacional de Educação, organizado pela Associação Brasileira de Educação, que teve por tema a Educação Física. Registrou o Inspetor que “depois de muitos dias de luta, procurando convencer aos homens do Governo a importancia do logar destinado a Minas, no Congresso da A.B.E., acabo de passar pela decepção de ver baldados todos os meus esforços”. Parece que o mal-estar com membros do Governo Mineiro estava instituído. 
Além de alegar os motivos de “ordem moral”, Andrade ainda afirmou que, por "amor proprio”, não compareceria ao VII CNE (Andrade, 1935, s.p.) ${ }^{8}$.

O término da Inspetoria de Educação Física estava próximo. Concorrendo para esse fim, Benedicto Valladares Ribeiro, à frente do Governo de Minas Gerais desde 1933, ansiava por uma reforma nos serviços da Secretaria da Educação e Saúde Pública. Em 1936, o Governador do Estado indicou essa vontade, alegando que, assim, completaria a obra de reconfiguração das Secretarias que já vinha operando. Em Mensagem, de 1936, apresentada à Assembleia Legislativa de Minas, Benedicto Valladares anunciou que pretendia “organizar nos mesmos modernos moldes, a secretaria da Educação e Saude Publica e expedir, para essa repartição, novo regulamento”, visto que as normas vigentes já não corresponderiam às “necessidades da administração” (MINAS GERAIS, 1936, p. 209-210). Em 1937, o Governador do Estado reafirmou essa aspiração, dizendo novamente, em Mensagem, que "necessitavam de melhor organização os serviços da Secretaria da Educação e Saúde Pública” (MINAS GERAIS, 1937, p. 219). Nesse movimento de remodelação, parecia não haver mais espaço para a Inspetoria de Educação Física.

No processo de decaimento, a publicação da Lei $\mathrm{n}^{0}$ 212, de 30 de outubro de 1937, que reorganizou os serviços da Secretaria da Educação e Saúde Pública, na qual não mais houve lugar para a Inspetoria e uma alteração na política do Estado referente à Educação Física e aos esportes em Minas, são também elementos que compõem o conjunto de vestígios sobre o declínio de tal órgão (SILVA, 2009). O Estado parecia vislumbrar outras políticas concernentes às práticas corporais sistematizadas e operou um deslocamento de intenções acerca da presença da Educação Física e dos esportes para o Minas Tênis Clube. O MTC foi fundado em 1935 mediante a fusão de dois grupos admiradores do esporte em Belo Horizonte. ${ }^{9}$ Benedicto Valladares, em solenidade de inauguração da piscina do MTC, em 28 de novembro de 1937, afirmou que aquele espaço, ao fazer uso de uma Educação Física racionalizada, fortaleceria o corpo e o caráter do povo. Em suas palavras, o MTC marcaria uma nova era para o Estado, "tornando o mineiro cada vez mais digno de suas tradições e cada vez mais brasileiro, para maior grandeza de nossa Pátria” (Jornal Minas Gerais, 1937, p. 4). O discurso pronunciado pelo major Ernesto Dorneles, então chefe de polícia que ocupava a presidência do Minas Tênis Clube, vai ao encontro daquilo expresso por Benedicto Valladares. Dizia o presidente do MTC que aquele espaço seria "uma fonte permanente de energias fisicas e morais, orientadas pelo ideal sublime de bem servir á nossa Pátria” (Jornal Minas Gerais, 1937, p. 4) . E prosseguia:

\footnotetext{
${ }^{8}$ Correspondência de Renato Andrade para Gustavo Lessa, que ocupou a presidência da Seção de Educação Física e Higiene, da Associação Brasileira de Educação. Documento presente no acervo da ABE.

${ }^{9}$ Um dos grupos pretendia fundar o Serra Tênis Clube, e o outro desejava organizar o Belo Horizonte Tênis Clube (RODRIGUES, 1996).
} 
É neste momento em que o Brasil renasce e cria novas fontes de vida e de prestigio, êsse espirito esportivo, que leva o homem a ser bravo sem deixar de ser cordial e compreensivo, prevalecerá aqui, e com êste propósito o Minas TenisClube contribuirá também para a grande obra, em que todos estamos empenhados, de tornar a Pátria maior e mais feliz (Jornal Minas Gerais, 1937, p. 4).

No projeto político configurado nos anos do Estado Novo, frequentemente as iniciativas educacionais objetivaram "a formação de uma consciência patriótica, de respeito aos valores maiores da Pátria e de manutenção da ordem social” (CUNHA JUNIOR, 1995, p. 198). Esses eixos passaram a orientar mais intensamente a prática dos esportes em Minas. Uma mudança fundamental na cena que passa a organizar a Educação Física e o esporte no Estado é a nomeação de militares para cargos no Minas Tênis Clube. Essa ocupação não foi tão bem-vinda durante a existência da Inspetoria de Educação Física, pois, naquele momento, quem cuidaria das iniciativas relacionadas ao ensino de tal disciplina seriam professores sintonizados com os ideários de renovação pedagógica que inspiraram a Reforma do Ensino de 1927.

Marilita Rodrigues (1996) afirma que, a partir de 1938, nas instalações do clube foram realizados cursos preparatórios para professoras de Educação Física que ministrariam aulas em grupos escolares. Tais cursos, que tiveram por conteúdo basilar proposições do Método Francês, foram dirigidos pela professora Luíza Macedo e pelo professor Antônio Macedo. Nenhum desses docentes figurou como colaborador nas ações da Inspetoria de Educação Física. Cabe perguntar por que não designar as Auxiliares e o antigo Inspetor de Educação Física para organizar e ministrar tais cursos no Minas Tênis Clube, já que acumulavam experiência na formação de professoras? Talvez por dificuldades de reorganização dos trabalhos da Secretaria da Educação e Saúde Pública, mas, sobretudo, por um provável desejo de ruptura com a recém-extinta Inspetoria, mais que isso, com o modelo adotado por esse órgão para a qualificação docente em Educação Física que não aderia a aspectos da instituição militar. Por sua vez, no curso proposto pelo Minas Tênis Clube, Rodrigues (1996) assevera que o principal referencial era o Método Francês, fundamentalmente inspirado no militarismo. Cabe ressaltar que já em 1929, tal Método foi considerado oficial para as aulas de Educação Física das escolas brasileiras. Contudo, a Inspetoria de Educação Física de Minas Gerais não se filiou a esse modelo de ensino e constituiu, durante seu período de existência, de 1927 a 1937, suas práticas referenciadas em uma cultura pedagógica permeada pelas necessidades biológicas, psicológicas e culturais dos alunos. Era uma Educação Física produzida, sobretudo, por dentro da escola.

No arranjo que permite compreender o declínio da Inspetoria, cabe ainda ressalvar que Renato Eloy de Andrade, pelo que indica sua família, já em 1937, encontrava-se adoentado. Em registros 
escritos deixados pelo seu pai, Manoel Eloy de Andrade, é possível evidenciar tal problema de saúde. Ele escreveu que Renato "ficou tuberculoso e sofreu durante tres longos anos". ${ }^{10}$ Renato Eloy faleceu em 21 de dezembro de 1939. Portanto, no processo de término da Inspetoria, ele provavelmente já estaria acometido pela tuberculose. Fato que também pode ter contribuído para o estabelecimento do fim da Inspetoria, uma vez que, doente, talvez já não estivesse em boas condições de argumentar em defesa do seu trabalho e dos avanços no ensino dessa disciplina em Minas Gerais. Também não mais poderia continuar ocupando o cargo de centralidade da Inspetoria de Educação Física. Por ato do governador do Estado, Renato Eloy aposentou-se como Inspetor de Educação Física em 7 de janeiro de 1938 (SILVA, 2009).

\section{Considerações finais}

A necessidade de qualificar o corpo docente das escolas mineiras não se circunscrevia à disciplina Educação Física. Era um imperativo do governo do presidente Antônio Carlos e do secretário responsável pelas questões do ensino, Francisco Campos. O discurso deste ao tomar posse na Secretaria do Interior, em 1926, é contundente ao afirmar que uma reforma do ensino primário não poderia ser desconectada de um professorado competente para operar a reconfiguração da instrução em Minas.

... não parece de boa razão, como muito bem accentuou o sr. Presidente do Estado, no seu recente e impressivo discurso de Barbacena, que o Estado se proponha ministrar uma instrucção primaria graduada e complexa, sem antes cuidar na formação de um professorado sufficientemente apto a exercer com efficiencia o graduado magisterio que se lhe incumbe. A instrucção primaria está em função do ensino normal. Este é que determina, estabelece e limita as possibilidades daquella. Uma instruç̧ão primaria graduada presupõe um apparelhamento normal de que ainda não estamos dotados. Ahi estão os elementos de um duplo programma: simplificar a instruç̧ão primaria de maneira a utilizar da maneira mais razoavel e mais util as aptidões do nosso professorado e cuidar nos apparelhos e processos de formação e aperfeiçoamento de um magisterio primário capaz de ministrar, com segurança e efficiencia, uma instrucção mais ampla e graduada (Jornal Minas Geraes, 1926a, p. 4).

Portanto, o procedimento de formar professoras específicas em Educação Física só pode ser compreendido a partir de dois aspectos que coexistiram. Primeiro, a necessidade do aperfeiçoamento do professorado, produzida no âmbito do governo estadual e, segundo o próprio movimento interno do processo de escolarização dessa disciplina.

As ações de qualificação do professorado promovidas pela Inspetoria permitem ver uma intencionalidade de produção de um projeto de Educação Física para as escolas. Não bastava sua presença nos programas de ensino, foi realizado um esforço para demarcá-la e configurá-la como

\footnotetext{
${ }^{10}$ Livro do Eloy, 14 de janeiro de 1940. Acervo pessoal Eloy de Andrade.
} 
uma disciplina escolar forjada, sobretudo, no campo educativo. As professoras que ministravam Educação Física nas escolas viram o ensino de tal matéria complexificar-se. Já não bastava que essas docentes possuíssem qualidades consideradas desejáveis ao professorado de Educação Física, citem-se habilidades corporais, destreza, bom humor. Aliada a essas características mostrava-se necessário uma direção técnica, que tomasse por objeto de estudo os procedimentos de ensino, as orientações científicas, a prescrição de conteúdos afinados com a proposta de renovação pedagógica. Ao eleger a Inspetoria de Educação Física como uma ocorrência histórica, concreta e particular, e investigar suas ações de formação docente, foi possível reconhecer elementos de constituição da disciplina que articulavam as características esperadas de uma professora de Educação Física, os conhecimentos necessários para ensinar, os métodos a serem empregados e os saberes que deveriam ser ministrados. Centralizadas no aperfeiçoamento de professoras primárias, a organização e a realização de cursos intensivos, bem como, a circulação de textos promovidas pela Inspetoria de Educação Física, aumentaram o grau de formalização no ensino de tal matéria.

\section{Fontes pesquisadas}

Andrade, Renato. [Correspondência]. Destinatário: Gustavo Lessa. Belo Horizonte, 21 jun. 1935.1 carta.

Boletim n. 18 "Educação Physica (Jogos e Callisthenia)": contribuição da Inspectoria da Educação Physica, Secretaria de Educação e Saude Publica, 1935.

Jornal Minas Geraes 1926a set 9; p. 4.

Jornal Minas Geraes 1926b nov 28; p. 6.

Jornal Minas Geraes 1928 out 5; p. 9.

Jornal Minas-Gerais 1933 jul 15; p. 4.

Jornal Minas Geraes 1935 out 9; p. 4.

Jornal Minas Gerais 1937 nov 30; p. 4.

MINAS GERAIS. Decreto n. 7.970-A. Approva o Regulamento do Ensino Primario. 15 de outubro de 1927. Collecção das Leis e Decretos (1927), vol. II, Belo Horizonte, 1928, p. 1170-1171.

MINAS GERAIS. Mensagem apresentada à Assembléia Legislativa de Minas Gerais, em sua sessão ordinária de 1936, pelo Governador do Estado. Belo Horizonte, 1936. p. 209-210.

MINAS GERAIS. Mensagem apresentada à Assembléia Legislativa de Minas Gerais, em sua sessão ordinária de 1937, pelo Governador do Estado. Belo Horizonte, 1937. p. 219.

Necessidade da criação da Escola de Educação Física e Desportos de Minas Gerais, sugestão apresentada ao Exmo. Snr. Governador do Estado de Minas Gerais, pedindo a criação de uma Escola de Educação Física e Desportos. jul. 1947, p.11.

Revista de Educação Física 1934 jan. n. 14; p. 25-26. 
Revista do Ensino 1925 set. n. 7; p. 186.

Revista do Ensino 1927 ago./set. n. 22; p. 502.

Revista do Ensino 1929 fev. n. 30; p. 36.

\section{Referências}

CARVALHO, Marta M. Chagas de. Reformas da Instrução Pública. In: LOPES, Eliane M. T.; FARIA FILHO, Luciano M.; VEIGA, Cynthia G. (Orgs.). 500 anos de educação no Brasil. 3 ed. 1 reimp. Belo Horizonte: Autêntica, 2007. p. 225-251.

CUNHA JUNIOR, Carlos Fernando Ferreira da. A Educação Física no Estado Novo: a questão do nacionalismo. In: III ENCONTRO NACIONAL DA HISTÓRIA DO ESPORTE, LAZER E EDUCAÇÃO FÍSICA. 1995, Curitiba. Anais eletrônicos...

FARIA, Miguel Fabiano de. A Educação Física na Revista do Ensino: produção de uma disciplina escolar em Minas Gerais. 2009. 145 f. Dissertação (Mestrado em Educação) - Faculdade de Educação da UFMG, Belo Horizonte, 2009.

FARIA FILHO, Luciano Mendes de. O processo de escolarização em Minas Gerais: questões teórico-metodológicas e perspectivas de pesquisa. In: VEIGA, Cynthia Greive; FONSECA, Thais Nivia de Lima e (orgs.). História e historiografia da educação no Brasil. Belo Horizonte: Autêntica, 2003. p. 77-97.

FARIA FILHO, Luciano Mendes de. Escolarização e cultura escolar no Brasil: reflexões em torno de alguns pressupostos e desafios. In: BENCOSTA, Marcus Levy (org.). Culturas escolares, saberes e práticas educativas: itinerários históricos. São Paulo: Cortez, v.1, 2007. p.191-211.

FRADE, Isabel Cristina A. da Silva; SILVA, Ceris Salete Ribas da. A leitura de textos oficiais: uma questão plural. In: Marinho, M, Silva, CSR (orgs.). Leituras do professor. Campinas: Mercado das Letras: Associação de Leitura do Brasil - ALB; 1998. p. 93-117.

RODRIGUES, Marilita Aparecida Arantes. Constituição do sentido moderno de esporte: pelas trilhas históricas do Minas Tênis Clube. Dissertação (Mestrado em Educação Física) - Escola de Educação Física da UFMG, Belo Horizonte, 1996.

SILVA, Giovanna Camila da. A partir da Inspetoria de Educação Física de Minas Gerais (19271937): movimentos para a escolarização da Educação Física no Estado. 2009. 228 f. Dissertação (Mestrado em Educação) - Faculdade de Educação da UFMG, Belo Horizonte, 2009.

VAGO, Tarcísio Mauro. A escolarização da gymnastica nas escolas normais de Minas Gerais (1883-1918). In: FERREIRA NETO, Amarílio (org.). Pesquisa Histórica na Educação Física. Vol. 2. Vitória: UFES/CEFD, 1997. p. 33-58.

VAGO, Tarcísio Mauro. Cultura escolar, cultivo de corpos: educação physica e gimnastica como práticas constitutivas dos corpos de crianças no ensino público primário de Belo Horizonte (19061920). Bragança Paulista: EDUSF, 2002. 